University of Nebraska - Lincoln

DigitalCommons@University of Nebraska - Lincoln

Public Health Resources

Public Health Resources

2016

Evaluation of potentially achievable vaccination coverage with simultaneous administration of vaccines among children in the United States

Zhen Zhao

National Center for Immunization and Respiratory Diseases, Centers for Disease Control and Prevention

Philip J. Smith

National Center for Immunization and Respiratory Diseases, Centers for Disease Control and Prevention,

Holly A. Hill

National Center for Immunization and Respiratory Diseases, Centers for Disease Control and Prevention,

Follow this and additional works at: http://digitalcommons.unl.edu/publichealthresources

Zhao, Zhen; Smith, Philip J.; and Hill, Holly A., "Evaluation of potentially achievable vaccination coverage with simultaneous administration of vaccines among children in the United States" (2016). Public Health Resources. 526.

http://digitalcommons.unl.edu/publichealthresources/526

This Article is brought to you for free and open access by the Public Health Resources at DigitalCommons@University of Nebraska - Lincoln. It has been accepted for inclusion in Public Health Resources by an authorized administrator of DigitalCommons@University of Nebraska - Lincoln. 


\title{
Evaluation of potentially achievable vaccination coverage with simultaneous administration of vaccines among children in the United States ${ }^{\text {th }}$
}

\author{
Zhen Zhao*, Philip J. Smith, Holly A. Hill \\ National Center for Immunization and Respiratory Diseases, Centers for Disease Control and Prevention, 1600 Clifton Road NE, MS A19, Atlanta, \\ GA 30329-4018, USA
}

\section{A R T I C L E I N F O}

\section{Article history:}

Received 12 February 2016

Received in revised form 25 April 2016

Accepted 29 April 2016

Available online 7 May 2016

\section{Keywords:}

Simultaneous administration

Childhood vaccines

Age appropriate

Potentially achievable

Vaccination coverage

Healthy People 2020 target

\begin{abstract}
A B S T R A C T
Background: Routine administration of all age-appropriate doses of vaccines during the same visit is recommended for children by the National Vaccine Advisory Committee (NVAC) and the Advisory Committee on Immunization Practices (ACIP).

Methods: Evaluate the potentially achievable vaccination coverage for $\geq 4$ doses of diphtheria and tetanus toxoids and acellular pertussis vaccine (4+DTaP), $\geq 4$ doses of pneumococcal conjugate vaccine (4+PCV), and the full series of Haemophilus influenzae type b vaccine (Hib-FS) with simultaneous administration of all recommended childhood vaccines. Compare the potentially achievable vaccination coverage to the reported vaccination coverage for calendar years 2001 through 2013; by state in the United States and by selected socio-demographic factors in 2013 . The potentially achievable vaccination coverage was defined as the coverage possible for the recommended 4+DTaP, 4+PCV, and Hib-FS if missed opportunities for simultaneous administration of all age-appropriate doses of vaccines for children had been eliminated. Results: Compared to the reported vaccination coverage, the potentially achievable vaccination coverage for 4+DTaP, 4+PCV, and Hib-FS could have increased significantly $(P<0.001)$, the vaccination coverage would have achieved the $90 \%$ target of Healthy People 2020 for the three vaccines beginning in 2005, 2008, and 2011 respectively. In 2013, the potentially achievable vaccination coverage increased significantly across all selected socio-demographic factors, potentially achievable vaccination coverage would have reached the $90 \%$ target for more than $51 \%$ of the states in the United States.

Conclusions: The findings in this study suggest that fully utilization of all opportunities for simultaneous administration of all age-eligible childhood doses of vaccines during the same vaccination visit is a critical strategy for achieving the vaccination coverage target of Healthy People 2020. Encouraging providers to deliver all recommended vaccines that are due at each visit by implementing client reminder and recall systems might decrease missed opportunities for simultaneous administration of childhood vaccines.
\end{abstract}

Published by Elsevier Ltd.

\section{Introduction}

Routine administration of all age-appropriate doses of childhood vaccines during the same health care provider visit is the standard for childhood immunization practices and has been approved and recommended by the National Vaccine Advisory

\footnotetext{
is Disclaimer: The findings and conclusions in this article are solely the responsibility of the authors and do not necessarily represent the official view of Centers for Disease Control and Prevention.

* Corresponding author. Tel.: +1 404639 8238; fax: +1 4046393266.

E-mail address: zaz0@cdc.gov (Z. Zhao).
}

Committee (NVAC), the Advisory Committee on Immunization Practices (ACIP), the American Academy of Pediatrics (AAP), and the American Academy of Family Physicians (AAFP) [1]. Simultaneous administration of childhood vaccines is defined as administering more than one recommended vaccine on the same visit day, at different anatomic sites, and not combined in the same syringe [2]. Simultaneous administration of all vaccines for which a child is eligible is an important strategy for ensuring that vaccinations are received on schedule, and for bringing children who have fallen behind on their vaccines up to date [3]. It is also an important standard crucial to increasing immunization rate, achieving and maintaining the national target of vaccination coverage level among children of 19-35 months for all recommended vaccines 
[1-5]. Experimental evidence and extensive clinical experience show that giving all age-appropriate childhood vaccines simultaneously is a safe and efficacious practice $[2,3,6]$. Data from vaccination coverage surveys have indicated that failing to administer all vaccines for which a child is eligible is an important cause of low vaccination coverage [3]. Surveys of vaccination records from 21 selected cities and localities in the United States have shown that each child had many opportunities for the simultaneous administration of vaccines that, if used appropriately, could have potentially raised vaccination coverage levels by $12-22$ percentage points with median of 17 percentage points [7]. A recent study from Nebraska has reported that $77 \%$ of children who were behind on their vaccinations at 24 months could have been up to date if appropriate vaccines had been given simultaneously [8]. A study from immunization record audits in the State of Georgia has demonstrated that vaccination coverage increased significantly when missed opportunities to administer vaccines simultaneously were reduced [9]. Missed opportunities for simultaneous vaccinations were recognized as one of the two main causes for children falling behind in their vaccination [10].

The studies cited above indicate that simultaneous administration of age-appropriate childhood vaccine could have increased children's vaccination coverage rates significantly, but those results were limited to the selected states and local areas and did not evaluate the vaccination coverage that could be potentially achieved at the national level. Since 1995, the Centers for Disease Control and Prevention $(\mathrm{CDC})$ has been estimating and reporting national, state, and selected local area vaccination coverage among children 19-35 months in the United States [11]. Those reports point out that vaccination coverage levels for most of the routine childhood vaccines have reached the Healthy People 2020 target of $90 \%$ [4]. However, vaccination coverage for $\geq 4$ doses of diphtheria and tetanus toxoids and acellular pertussis vaccine (4+DTaP), $\geq 4$ doses of pneumococcal conjugate vaccine ( $4+\mathrm{PCV})$, and the full series of Haemophilus influenzae type b vaccine (Hib-FS) have not yet reached the $90 \%$ target. Therefore, in this current study, we applied the important immunization practice standard, i.e. simultaneous administration of childhood vaccines at the same visit, to the National Immunization Survey (NIS), the largest vaccination survey in the United States. We evaluated the potentially achievable vaccination coverage for $4+\mathrm{DTaP}, 4+\mathrm{PCV}$, and Hib-FS for calendar years 2001 through 2013 in the United States; by 50 U.S. states and DC, and by selected socio-demographic factors in 2013. All potentially achievable vaccination coverage levels were compared to the corresponding reported vaccination coverage levels to assess the impact of simultaneous administration of childhood vaccines on vaccination coverage.

\section{Methods}

\subsection{Data sources}

National Immunization Survey (NIS) data collected from 2001 through 2013 were analyzed in this study. The NIS is conducted annually by the Centers for Disease Control and Prevention (CDC) to obtain national, state, and selected local area estimates of vaccination coverage for the U.S. non-institutionalized population of children 19-35 months [11]. The NIS is a random-digit-dialed telephone survey of households with age eligible children followed by a mail survey to children's immunization providers to obtain provider-reported vaccination histories. Smith et al. [12] provide a detailed description of the complex survey design used by the NIS, which has been approved by CDC Institutional Review Board. Detailed descriptions of the 2001-2013 NIS and corresponding response rates have been published elsewhere [13-16].

\subsection{Selected socio-demographic factors}

The following socio-demographic factors available in the NIS related to the child, mother, family, and vaccination provider which have previously been found to be associated with childhood vaccination coverage in the United States were evaluated in this study, including child's first born status (yes vs. no), number of children in the family ( 1 vs. $\geq 2$ ), family poverty level (at/above vs. below poverty), family locality (urban, suburban, rural), mobility status since birth (not moved vs. moved), education level of mother $(\leq 12$ years vs. $\geq 13$ years), marital status of mother (married vs. not married), age group of mother ( $\leq 29$ years vs. $\geq 30$ years), and number ( 1 vs. $\geq 2$ ) and type (public, other, private) of child's vaccination providers. Children were defined as having health insurance if they were covered through the parents' employer or union or by Medicaid, S-CHIP, the Indian Health Service, Military Health Care, Tricare, Champus, Champ-VA, other health insurance, or another health care plan.

\subsection{Outcome measures and definitions}

Vaccines are recommended by ACIP for children during the first 2 years of life to protect them against 14 vaccine-preventable diseases and include: varicella, Haemophilus influenzae type b (Hib), measles, mumps, and rubella (MMR), rotavirus (RV), pneumococcal conjugate vaccine (PCV), diphtheria and tetanus toxoids and acellular pertussis (DTaP), inactivated poliovirus (IPV), hepatitis A(HepA), hepatitis $B(\mathrm{HepB})$, and influenza vaccines $[4,17]$. As reported by $\mathrm{CDC}$, the vaccination coverage for $3+\mathrm{DTaP}, 3+\mathrm{PCV}$, and the primary series of Haemophilus influenzae type b (Hib-PS) have reached the $90 \%$ target for years, but for $4+\mathrm{DTaP}, 4+\mathrm{PCV}$, and the full series of Haemophilus influenzae type $\mathrm{b}$ (Hib-FS), the vaccination coverage have not achieved the $90 \%$ target yet [11]. Therefore we must focus on the last dose of vaccines in those 3 vaccination series. A missed opportunity was defined as the failure to administer the fourth dose of DTaP, the fourth dose of PCV, and the booster dose of Hib vaccine for the full series of Hib (Hib-FS), and during the same age eligible period, for the 3 vaccines just mentioned, when a child received one or more other needed and age appropriate vaccines [7]. Potentially achievable vaccination coverage was defined as the maximum coverage possible for the recommended $4+\mathrm{DTaP}, 4+\mathrm{PCV}$, and Hib-FS if missed opportunities defined above had been eliminated [7].

The primary series of Haemophilus influenzae type b (Hib-PS) includes $\geq 2$ or $\geq 3$ doses of Hib vaccine depending on product type. The full series of Haemophilus influenzae type $b$ (Hib-FS) includes $\geq 3$ or $\geq 4$ doses of Hib vaccine depending on product type received (i.e. includes the primary series plus the booster dose). In this current study, data analyses for Hib were limited to 2011-2013 because a shortage of Hib vaccine occurred in the United States during December 2007-September 2009 which resulted in an interim recommendation to defer the booster dose of Hib for Hib-FS; children included in the 2009 and 2010 NIS samples were affected by the temporary recommendation to suspend the booster dose of Hib for Hib-FS vaccine [13].

Because the pneumococcal conjugate vaccine shortages during 2001-2004 in the United States, the CDC recommended that all health care providers temporarily suspend routine administration of the fourth doses of PCV, thus children included in the 2001-2004 samples were affected by the deferring of the fourth dose of PCV [18]. Therefore the data from NIS 2005 to 2013 were included and analyzed for the PCV vaccination study.

\subsection{Statistical analyses}

All of the analyses in this study were performed using SAS callable SUDAAN 11.0.0 [19], which properly accounts for the 


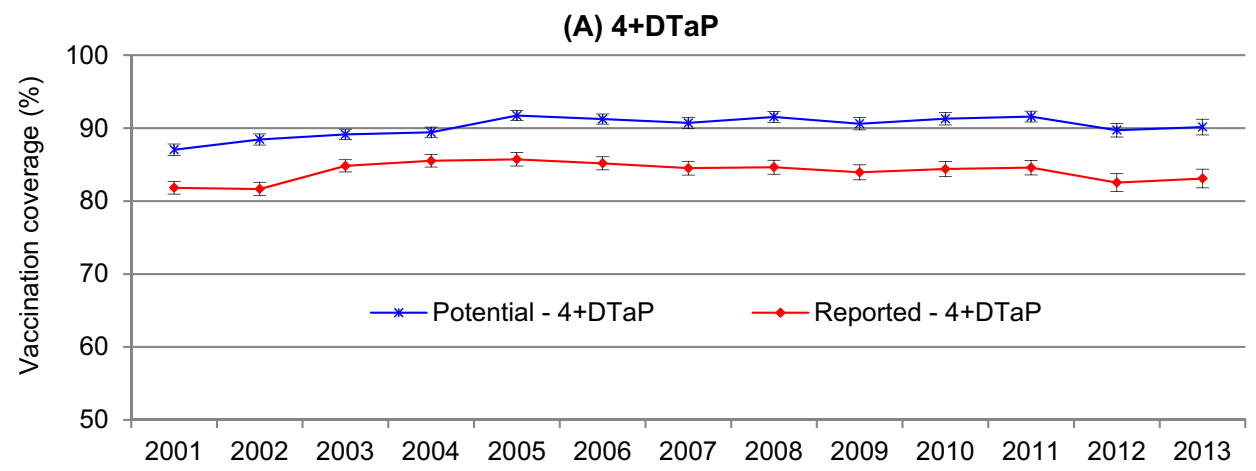

(B) $4+\mathrm{PCV}$

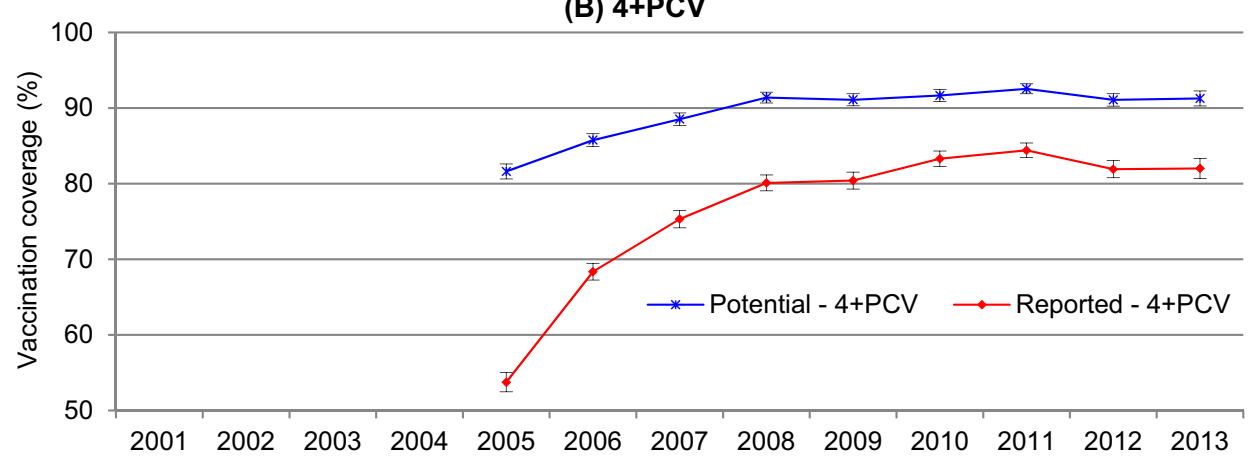

(C) Hib-FS

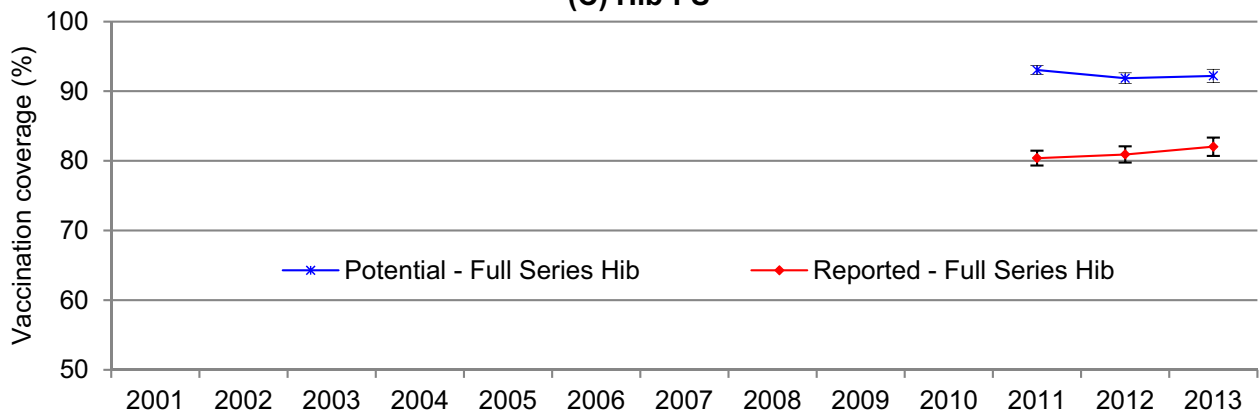

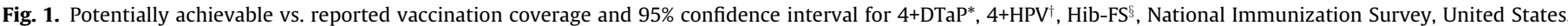

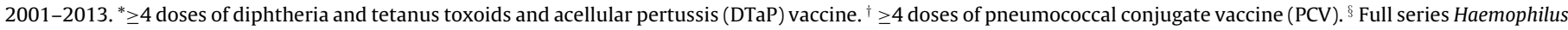

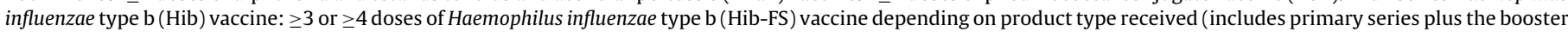

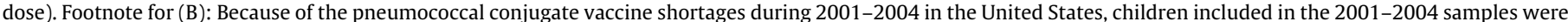

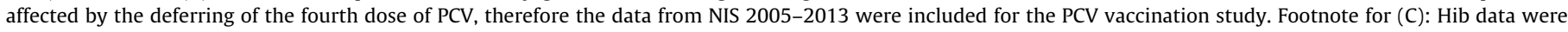

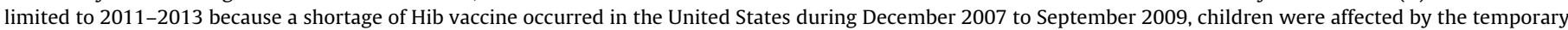
recommendation to suspend the booster dose of Hib for Hib-FS vaccine.

complex sampling survey design in the NIS. The potentially achievable and reported vaccination coverage, and the 95\% confidence interval $(\mathrm{CI})$ were estimated with weighted categorical data analyses procedures; $t$-tests were applied to compare the potentially achievable vaccination coverage with the reported vaccination coverage. The NIS methodology has been approved annually by the Ethics and Research Review Board of the National Center for Health Statistics since it was initiated in 1994.

\section{Results}

\subsection{Potentially achievable}

vs. reported vaccination coverage for $4+D T a P, 4+P C V$, and the full series of Hib (Hib-FS), 2001-2013

If the recommended standards of childhood immunization practices for simultaneous administration of the fourth dose of DTaP vaccine had been implemented fully according to the general ACIP recommended vaccination schedule, compared to the reported vaccination coverage for 4+DTaP, the potentially achievable vaccination coverage for 4+DTaP would have increased significantly each year from 2001 through $2013(P<0.001)$ (Fig. 1(A)). The increases of vaccination coverage ranged from 3.9 percentage points to 7.2 percentage points with median of 6.7 percentage points. During 2001-2013, the potentially achievable vaccination coverage for $4+\mathrm{DTaP}$ would have reached or been very close to the $90 \%$ target. Specifically beginning in 2005, the potentially achievable vaccination coverage for $4+\mathrm{DTaP}$ would have reached or surpassed the $90 \%$ target specified by Healthy People 2020.

If missed opportunities for simultaneous administration of the fourth dose of PCV had been eliminated, the potentially achievable vaccination coverage for $4+\mathrm{PCV}$ would be significantly higher than the reported vaccination coverage $(P<0.001)$ (Fig. 1(B)). Beginning in 2008 , the potentially achievable vaccination coverage for $4+\mathrm{PCV}$ would have reached and been significantly higher than the $90 \%$ target $(P<0.05)$. Simultaneous administration could have significantly increased the coverage for $4+\mathrm{PCV}$ by 8.1 percentage points to 31.1 percentage points with median increase of 12.2 percentage points. 
Table 1

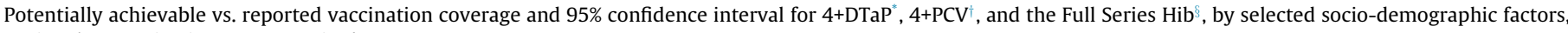
National Immunization Survey, United States, 2013.

\begin{tabular}{|c|c|c|c|c|c|c|c|}
\hline \multirow[t]{2}{*}{ Factors } & & \multicolumn{2}{|l|}{ 4+DTaP } & \multicolumn{2}{|l|}{$4+\mathrm{PCV}$} & \multicolumn{2}{|l|}{ Full Series Hib } \\
\hline & & $\begin{array}{l}\text { Potentially achievable } \\
\%\left(95 \% \mathrm{CI}^{\mp}\right)\end{array}$ & $\begin{array}{l}\text { Reported } \\
\%(95 \% \mathrm{CI})\end{array}$ & $\begin{array}{l}\text { Potentially achievable } \\
\%(95 \% \mathrm{CI})\end{array}$ & $\begin{array}{l}\text { Reported } \\
\%(95 \% \mathrm{CI})\end{array}$ & $\begin{array}{l}\text { Potentially achievable } \\
\%(95 \% \mathrm{CI})\end{array}$ & $\begin{array}{l}\text { Reported } \\
\%(95 \% \mathrm{CI})\end{array}$ \\
\hline US National & & $90.1 \pm 1.1^{* *}$ & $83.1 \pm 1.3$ & $91.3 \pm 1.0^{* * *}$ & $82.0 \pm 1.3$ & $92.2 \pm 0.9^{* *}$ & $82.0 \pm 1.3$ \\
\hline $\begin{array}{l}\text { Health insurance of } \\
\text { child }\end{array}$ & $\begin{array}{l}\text { No } \\
\text { Yes }\end{array}$ & $\begin{array}{l}86.8 \pm 2.2 \\
90.9 \pm 1.2^{* *}\end{array}$ & $\begin{array}{l}77.0 \pm 3.0 \\
84.5 \pm 1.4\end{array}$ & $\begin{array}{l}86.9 \pm 2.3 \\
92.3 \pm 1.1^{* *}\end{array}$ & $\begin{array}{l}74.8 \pm 2.8 \\
83.7 \pm 1.5\end{array}$ & $\begin{array}{l}89.1 \pm 2.1 \\
92.9 \pm 1.1^{* *}\end{array}$ & $\begin{array}{l}75.9 \pm 3.0 \\
83.5 \pm 1.5\end{array}$ \\
\hline Family poverty level & $\begin{array}{l}\text { Below } \\
\text { At/above }\end{array}$ & $\begin{array}{l}87.4 \pm 2.3 \\
91.6 \pm 1.1^{* *}\end{array}$ & $\begin{array}{l}77.8 \pm 2.7 \\
86.0 \pm 1.3\end{array}$ & $\begin{array}{l}87.5 \pm 2.3 \\
93.1 \pm 0.9^{* *}\end{array}$ & $\begin{array}{l}74.5 \pm 2.7 \\
86.1 \pm 1.4\end{array}$ & $\begin{array}{l}89.0 \pm 2.2 \\
93.8 \pm 0.9^{* *}\end{array}$ & $\begin{array}{l}75.8 \pm 2.8 \\
85.3 \pm 1.4\end{array}$ \\
\hline First born child & $\begin{array}{l}\text { No } \\
\text { Yes }\end{array}$ & $\begin{array}{l}88.5 \pm 1.5 \\
92.7 \pm 1.4^{* *}\end{array}$ & $\begin{array}{l}80.2 \pm 1.8 \\
87.5 \pm 1.7\end{array}$ & $\begin{array}{l}90.2 \pm 1.4^{* *} \\
92.9 \pm 1.3^{* *}\end{array}$ & $\begin{array}{l}79.3 \pm 1.8 \\
86.1 \pm 1.8\end{array}$ & $\begin{array}{l}91.0 \pm 1.3^{* *} \\
94.0 \pm 1.2^{* *}\end{array}$ & $\begin{array}{l}79.0 \pm 1.8 \\
86.6 \pm 1.7\end{array}$ \\
\hline $\begin{array}{l}\text { Number of children in } \\
\text { family }\end{array}$ & $\begin{array}{l}1 \\
\geq 2\end{array}$ & $\begin{array}{l}92.4 \pm 1.8^{* *} \\
89.3 \pm 1.3\end{array}$ & $\begin{array}{l}86.6 \pm 2.1 \\
81.7 \pm 1.6\end{array}$ & $\begin{array}{l}92.7 \pm 1.7^{* *} \\
90.7 \pm 1.2^{* *}\end{array}$ & $\begin{array}{l}85.7 \pm 2.2 \\
80.5 \pm 1.6\end{array}$ & $\begin{array}{l}93.7 \pm 1.6^{* *} \\
91.6 \pm 1.2^{* *}\end{array}$ & $\begin{array}{l}86.2 \pm 2.2 \\
80.3 \pm 1.6\end{array}$ \\
\hline Family locality & $\begin{array}{l}\text { Urban } \\
\text { Suburban } \\
\text { Rural }\end{array}$ & $\begin{array}{l}91.8 \pm 3.5^{* *} \\
93.1 \pm 2.9^{* *} \\
92.8 \pm 3.3^{* *}\end{array}$ & $\begin{array}{l}84.2 \pm 4.2 \\
83.8 \pm 4.2 \\
85.9 \pm 4.4\end{array}$ & $\begin{array}{l}92.5 \pm 2.9^{* * *} \\
92.0 \pm 3.3^{* *} \\
90.1 \pm 4.0^{* *}\end{array}$ & $\begin{array}{l}84.8 \pm 4.1 \\
84.2 \pm 3.9 \\
77.7 \pm 5.6\end{array}$ & $\begin{array}{l}95.2 \pm 2.2^{* *} \\
93.2 \pm 2.9^{* *} \\
92.2 \pm 3.7^{* *}\end{array}$ & $\begin{array}{l}85.7 \pm 3.7 \\
82.9 \pm 4.3 \\
79.3 \pm 5.5\end{array}$ \\
\hline Family mobility & $\begin{array}{l}\text { Moved } \\
\text { Not moved }\end{array}$ & $\begin{array}{l}86.2 \pm 3.5 \\
90.6 \pm 1.1^{* *}\end{array}$ & $\begin{array}{l}75.5 \pm 4.7 \\
83.9 \pm 1.3\end{array}$ & $\begin{array}{l}85.2 \pm 3.6 \\
91.9 \pm 1.0^{* *}\end{array}$ & $\begin{array}{l}71.7 \pm 4.4 \\
83.1 \pm 1.4\end{array}$ & $\begin{array}{l}87.1 \pm 3.1 \\
92.8 \pm 1.0^{* * *}\end{array}$ & $\begin{array}{l}72.3 \pm 4.8 \\
83.1 \pm 1.4\end{array}$ \\
\hline $\begin{array}{l}\text { Education level of } \\
\text { mother }\end{array}$ & $\begin{array}{l}\leq 12 \text { years } \\
\geq 13 \text { years }\end{array}$ & $\begin{array}{l}87.6 \pm 2.0 \\
92.2 \pm 1.1^{* *}\end{array}$ & $\begin{array}{l}79.3 \pm 2.3 \\
86.1 \pm 1.3\end{array}$ & $\begin{array}{l}88.8 \pm 1.9 \\
93.2 \pm 1.0^{* *}\end{array}$ & $\begin{array}{l}76.5 \pm 2.4 \\
86.4 \pm 1.4\end{array}$ & $\begin{array}{l}90.4 \pm 1.7^{* *} \\
93.6 \pm 1.0^{* *}\end{array}$ & $\begin{array}{l}77.8 \pm 2.4 \\
85.4 \pm 1.4\end{array}$ \\
\hline $\begin{array}{l}\text { Marital status of } \\
\text { mother }\end{array}$ & $\begin{array}{l}\text { Married } \\
\text { Not married }\end{array}$ & $\begin{array}{l}91.7 \pm 1.1^{* *} \\
87.6 \pm 2.1\end{array}$ & $\begin{array}{l}85.5 \pm 1.4 \\
79.0 \pm 2.5\end{array}$ & $\begin{array}{l}92.7 \pm 1.0^{* *} \\
88.9 \pm 2.0\end{array}$ & $\begin{array}{l}84.5 \pm 1.5 \\
77.9 \pm 2.5\end{array}$ & $\begin{array}{l}93.9 \pm 0.9^{* *} \\
89.4 \pm 2.0\end{array}$ & $\begin{array}{l}84.0 \pm 1.5 \\
78.7 \pm 2.5\end{array}$ \\
\hline Age group of mother & $\begin{array}{l}\leq 29 \text { years } \\
\geq 30 \text { years }\end{array}$ & $\begin{array}{l}87.0 \pm 1.9 \\
92.7 \pm 1.2^{* *}\end{array}$ & $\begin{array}{l}78.1 \pm 2.3 \\
87.1 \pm 1.4\end{array}$ & $\begin{array}{l}89.1 \pm 1.7 \\
93.0 \pm 1.1^{* *}\end{array}$ & $\begin{array}{l}77.8 \pm 2.3 \\
85.4 \pm 1.6\end{array}$ & $\begin{array}{l}90.1 \pm 1.7^{* *} \\
93.9 \pm 1.1^{* *}\end{array}$ & $\begin{array}{l}77.8 \pm 2.3 \\
85.5 \pm 1.5\end{array}$ \\
\hline $\begin{array}{l}\text { Number of vaccination } \\
\text { providers }\end{array}$ & $\begin{array}{l}1 \\
\geq 2\end{array}$ & $\begin{array}{l}91.0 \pm 1.3^{* *} \\
88.5 \pm 1.9\end{array}$ & $\begin{array}{l}84.0 \pm 1.5 \\
81.4 \pm 2.3\end{array}$ & $\begin{array}{l}92.3 \pm 1.2^{* * *} \\
89.3 \pm 1.9\end{array}$ & $\begin{array}{l}83.5 \pm 1.6 \\
79.2 \pm 2.4\end{array}$ & $\begin{array}{l}93.3 \pm 1.1^{* *} \\
90.2 \pm 1.8^{* *}\end{array}$ & $\begin{array}{l}83.3 \pm 1.6 \\
79.5 \pm 2.3\end{array}$ \\
\hline $\begin{array}{l}\text { Type of vaccination } \\
\text { providers }\end{array}$ & $\begin{array}{l}\text { Public } \\
\text { Other } \\
\text { Private }\end{array}$ & $\begin{array}{l}90.2 \pm 2.4^{* * *} \\
88.7 \pm 1.9 \\
92.0 \pm 1.5^{* *}\end{array}$ & $\begin{array}{l}80.1 \pm 3.8 \\
82.4 \pm 2.1 \\
85.2 \pm 1.7\end{array}$ & $\begin{array}{l}87.4 \pm 3.0 \\
89.8 \pm 1.7 \\
94.1 \pm 1.3^{\text {** }}\end{array}$ & $\begin{array}{l}74.6 \pm 4.0 \\
81.3 \pm 2.2 \\
85.1 \pm 1.8\end{array}$ & $\begin{array}{l}89.9 \pm 2.5 \\
90.1 \pm 1.8^{* *} \\
95.0 \pm 1.2^{* *}\end{array}$ & $\begin{array}{l}76.1 \pm 4.4 \\
80.9 \pm 2.2 \\
85.0 \pm 1.7\end{array}$ \\
\hline
\end{tabular}

* $\geq 4$ doses of diphtheria and tetanus toxoids and acellular pertussis (DTaP) vaccine.

$\dagger \geq 4$ doses of pneumococcal conjugate vaccine (PCV).

$\S$ Full series Haemophilus influenzae type b (Hib) vaccine: $\geq 3$ or $\geq 4$ doses of Haemophilus influenzae type b (Hib-FS) vaccine depending on product type received (includes primary series plus the booster dose).

$95 \%$ Confidence Interval.

** Potentially achievable vaccination coverage would have reached the $90 \%$ target.

If all opportunities for simultaneous administration of the booster dose of Hib vaccine for Hib-FS had been taken, compared to the reported vaccination coverage for the full series of Hib, the potentially achievable vaccination coverage for the Hib-FS would have increased 10.2 percentage points to 12.6 percentage points with median increase of 10.9 percentage points (Fig. 1(C)). The potentially achievable vaccination coverage for the full series of $\mathrm{Hib}$ would have been significantly higher than the reported vaccination coverage $(P<0.001)$. The potentially achievable vaccination coverage for the Hib-FS would have reached the $90 \%$ target beginning in 2011.

\subsection{Potentially achievable vs. reported vaccination coverage by selected socio-demographic factors in 2013}

Potentially achievable vaccination coverage was compared to the reported vaccination coverage for $4+\mathrm{DTaP}, 4+\mathrm{PCV}$, and the full series of Hib by selected socio-demographic factors (Table 1 ). If all opportunities for simultaneous administration of the fourth dose of DTaP, the fourth dose of PCV, and the booster dose of Hib vaccine for the full series of Hib (Hib-FS) had been used, compared to the reported vaccination coverage, the potentially achievable vaccination coverage would have increased significantly across each of the eleven selected socio-demographic factors for the three vaccine series at levels of $P<0.05, P<0.01$, and $P<0.01$ respectively. The potentially achievable vaccination coverage for $4+\mathrm{DTaP}$ would have increased by 5.2 percentage points to 10.7 percentage points (median 7.1 percentage points), for $4+\mathrm{PCV}$ by 6.8 percentage points to 13.5 percentage points (median 8.9 percentage points), for the full series of Hib by 7.4 percentage points to 14.8 percentage points (median 10.1 percentage points) across each of the eleven sociodemographic factors. The reported vaccination coverage for 4+DTaP was significantly lower than the Healthy People 2020 target of $90 \%$ at level of $P<0.01$ over all selected socio-demographic factors except rural area, for which the difference was not significant at level of $P<0.05$. The reported vaccination coverages for $4+\mathrm{PCV}$ and the full series of Hib were significantly lower than the Healthy People 2020 target of $90 \%$ at level of $P<0.05$ across all selected socio-demographic factors. However, the potentially achievable vaccination coverage would have reached the $90 \%$ target for 14 , 15 , and 19 categories out of the total 24 categories from the 11 factors by $4+\mathrm{DTaP}, 4+\mathrm{PCV}$, and the full series of $\mathrm{Hib}$ respectively as presented in Table 1.

\subsection{Potentially achievable vs. reported vaccination coverage by state in the United States in 2013}

If the fourth dose of DTaP had been administered simultaneously at all opportunities available, compared to the reported vaccination coverage, the potentially achievable vaccination coverage for $4+$ DTaP could have increased in 49 states and DC by 2.2 percentage points to 12.7 percentage points (median 7.1 percentage points) (Fig. 2(A)). The only exception is Nevada for which an increase of $0.51 \%$ was observed. Moreover, for 19 states and DC, the potentially 

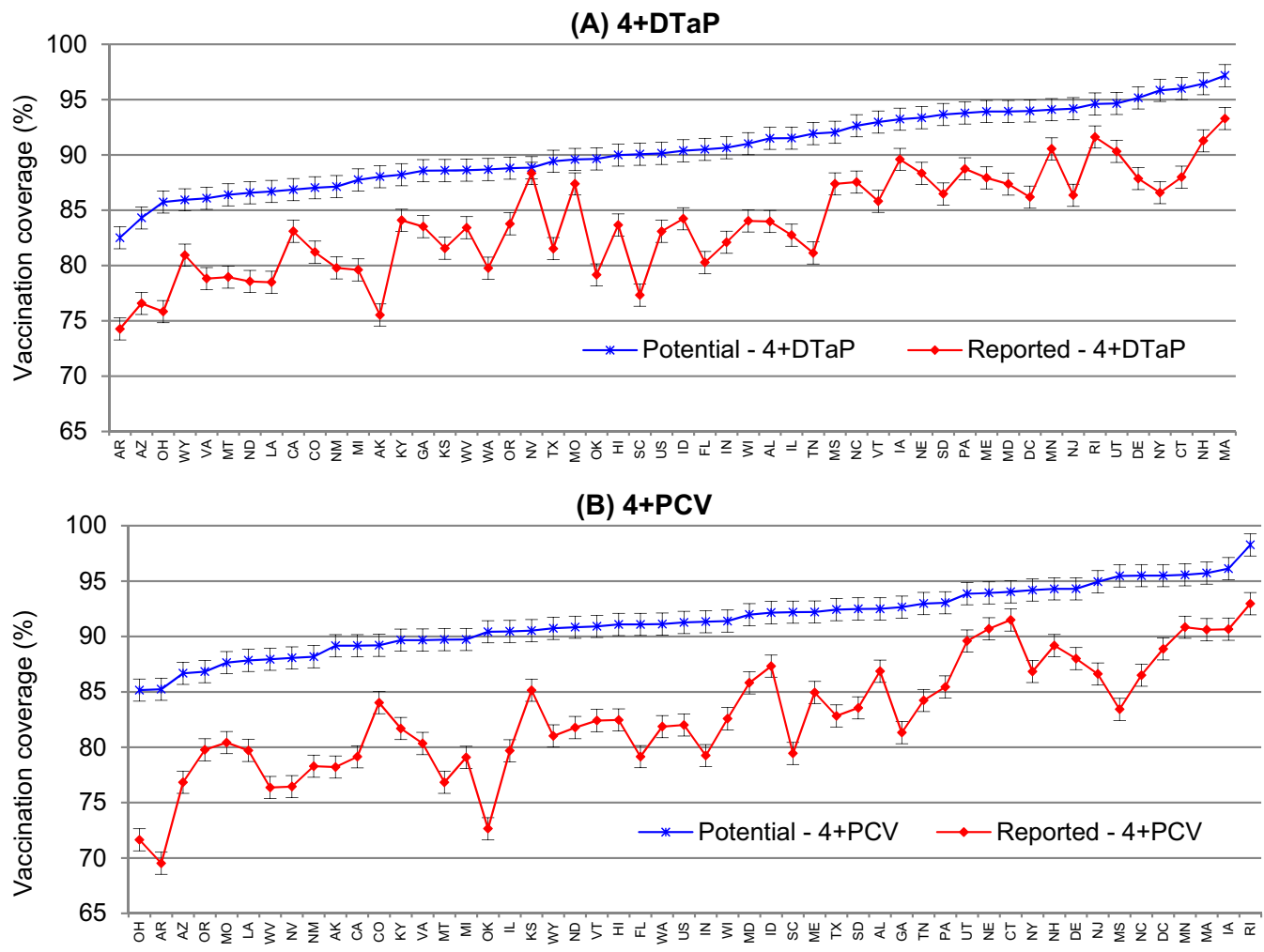

(C) Hib-FS

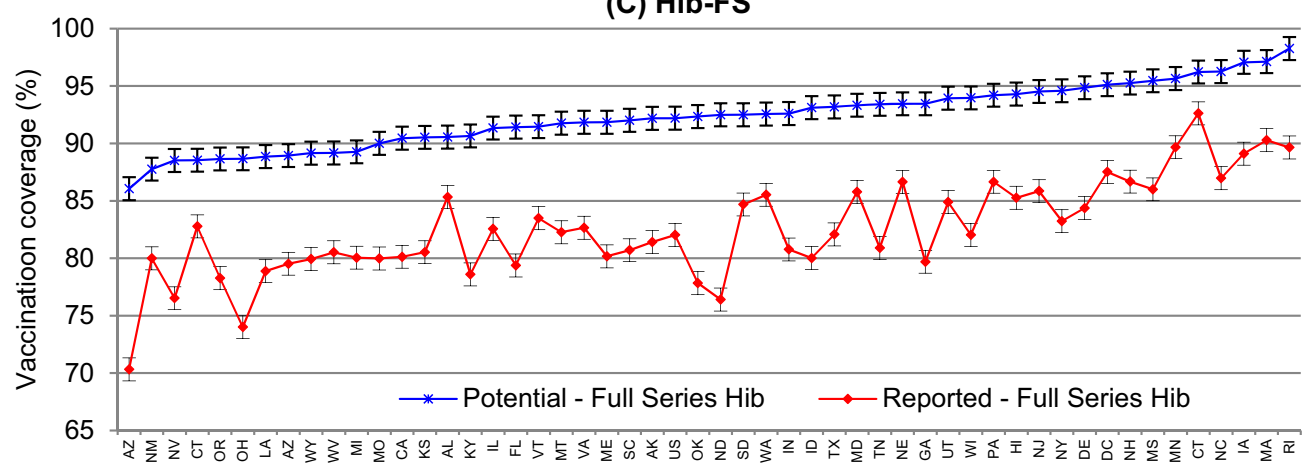

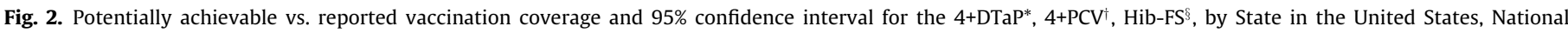

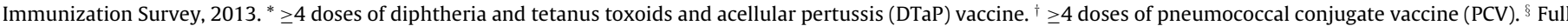

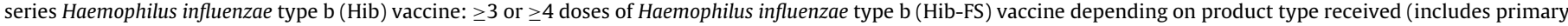
series plus the booster dose).

achievable vaccination coverage would have increased significantly at level of $P<0.05$. On the reported vaccination coverage for 4+DTaP, only five states reached the $90 \%$ vaccination coverage target; however, for the potentially achievable vaccination coverage, 27 states and DC would have reached 90\% target in 2013.

If all opportunities for simultaneous administration of the fourth dose of PCV had been used appropriately, compared to the reported vaccination coverage, the potentially achievable vaccination coverage for $4+\mathrm{PCV}$ would have increased across all 50 states and DC by 2.5 percentage points to 17.8 percentage points (median 8.8 percentage points) (Fig. 2(B)). In addition, for 32 states and DC the potentially achievable vaccination coverage would have increased significantly at level of $P<0.05$. On the reported vaccination coverage for $4+\mathrm{PCV}$, only six states achieved the $90 \%$ target; however, for the potentially achievable vaccination coverage, 35 states and DC would have reached the 90\% target in 2013.

Had the recommendation for simultaneous administration of the booster dose of Hib for Hib-FS been in effect and adhered to, compared to the reported vaccination coverage, the potentially achievable vaccination coverage for the full series of Hib would have increased across all 50 states and DC (Fig. 2(C)) by 3.6 percentage points to 16.1 percentage points (median 9.4 percentage points). Also, for 42 states and DC the potentially achievable vaccination coverage would have increased significantly at level of $P<0.05$. On the reported coverage for full series of Hib, only two states reached the $90 \%$ target; however, for the potentially achievable vaccination coverage, 39 states and DC would have reached the $90 \%$ target in 2013.

\section{Discussion}

Immunization recommendations in the United States currently target 14 vaccine-preventable diseases for children [4,17], it is very important to achieve the national immunization targets for children outlined in the Healthy People 2020, a nationwide health promotion and disease prevention agenda from the US Department of Health and Human Services. Achieving these objectives 
will improve the health and welfare of all children as well as the communities in which they live [4]. However, the regular calendar year estimates of vaccination coverage based on NIS indicate that the reported vaccination coverage for $4+\mathrm{DTaP}, 4+\mathrm{PCV}$, and the full series of Hib for the U.S national and the majority of the states in the United States have been well below the 90\% target level for years [11]. In order to increase vaccination coverage levels, one of the Immunization Strategies for Healthcare Practices and Providers is to reduce missed opportunities for simultaneous administration of childhood vaccines [5]. This current study applied that strategy to NIS data and demonstrated that if missed opportunities for simultaneous administration of childhood vaccines had been eliminated, compared to the reported vaccination coverage, the potentially achievable vaccination coverage for $4+\mathrm{DTaP}, 4+\mathrm{PCV}$, and the full series of Hib would have increased significantly, and could have achieved the $90 \%$ target in the United States. Rapid rise in reported vaccination coverage for $4+\mathrm{PCV}$ between 2005 and 2008 likely reflects relative newness of PCV vaccine to the schedule (2000) and, in part, PCV shortages between 2001 and 2004.

An increasing proportion of children vaccination visits include simultaneous administration of childhood vaccines. Future introduction of new vaccines to protect against multiple diseases will further increase the number of injections at routine childhood vaccination visits. Parental and healthcare provider attitudes toward simultaneous administration of childhood vaccines may affect acceptance of recommended vaccines. An article [20] conducted a systematic review of the literature to examine factors underlying reported parental and healthcare provider concerns and practices related to simultaneous administration of childhood vaccines during the same vaccination visits. That study indicated that providers and parents report concerns about multiple vaccination, which tend to increase with increasing numbers of vaccination. Common parental and provider concerns included apprehension about the pain experienced by the child, worry about potential side effects, and uncertainty about vaccine effectiveness. That study pointed out that multiple studies reported that a positive provider recommendation to the parent and a high level of concern about the severity of the target disease were significantly associated with parental acceptance of simultaneous administration of childhood vaccines. Providers often significantly overestimated parental concerns about simultaneous vaccination, and their overestimation of parental concerns may lead them to postpone recommended vaccinations, which may result in extra visits and delayed vaccination. More research is needed on interventions to overcome provider and parental concern about simultaneous vaccination.

This study has some limitations that must be acknowledged. First, we assumed all visits for which we had data were eligible for vaccination. Because DTaP vaccination requires a minimum of 6 months interval between the third and fourth dose, we may have overestimated the frequency of missed opportunities for the fourth dose of DTaP and therefore overestimated the potentially achievable vaccination coverage for 4+DTaP. Second, we only evaluated healthcare visits when a vaccination was administered, however, there are other healthcare visits where missed opportunities may occur, such as acute care visits or follow-up visits. Therefore, in this current study, the assessment of the impact on vaccination coverage levels by eliminating missed opportunities for simultaneous administration of childhood vaccines is conservative [7]. Furthermore, if all of the other missed visit opportunities for childhood immunization could have been eliminated, then higher potentially achievable vaccination coverage levels might be attained. Finally, the annual surveys of the NIS from 2001 through 2010 used in this study collected data from households with a landline-phones, while the 2011 to 2013 surveys collected data from households with both landlines and cell-phones service.
However, recent studies [21,22] indicated that the survey nonresponse and non-coverage bias in estimates of vaccination coverage might be quite small, the total survey error followed a normal distribution with mean of 1.72 percentage points (95\% CI: $1.71-1.74$ percentage points) and final adjusted survey weights corrected for this error. Although small, the largest contributor to the total survey error in terms of magnitude was nonresponse of immunization providers.

Strategies designed to prevent missed opportunities have taken many different forms, used alone or in combination. Standing orders is the first. These are protocols whereby non-physician immunization personnel may vaccinate clients without direct physician involvement at the time of the immunization. Standing orders are implemented in settings such as clinics, hospitals, and nursing homes. When used alone or in combination with other interventions, standing orders have had positive effects on immunization rates among children. Provider education is the second strategy. Anyone responsible for administering immunizations should be knowledgeable about principles of vaccination and vaccination scheduling, to the extent required for their position. Providers are largely responsible for educating their patients, so an investment in provider education will result in a higher level of understanding about immunizations among the public in general. Numerous educational materials, in a variety of formats, are available from CDC, the Immunization Action Coalition, and some state health departments, hospitals, or professional organizations. Incorporating some AFIX principles (i.e., assessment, feedback) into a provider education program might have a greater effect on provider behavior than an education effort aimed only at increasing knowledge. The last strategy is the Provider reminder and recall systems which use client reminder and recall interventions to remind parents that vaccinations are due (reminders) or late (recall), while effective in increasing immunization levels, can also help avoid missed opportunities if they are a component of other practices directed toward this goal. For example, if a reminder system is used consistently and staff members are knowledgeable about vaccination opportunities and valid contraindications, the system can be an additional aid in promoting appropriate immunization practices $[5,23]$.

\section{Conclusions}

The findings in this study suggest that fully utilization of all opportunities for simultaneous administration of all age-eligible childhood doses of vaccines during the same vaccination visit is a critical strategy for achieving the vaccination coverage target of Healthy People 2020. If simultaneous administration of all age-appropriate doses of vaccines had been fully carried out according to the general ACIP recommended vaccination schedule, potentially achievable vaccination coverage for 4+DTaP, 4+PCV, and Hib-FS could have reached the $90 \%$ target of Healthy People 2020 at the levels of national, states, and socio-demographic factors in the United States. Encouraging providers to deliver all recommended vaccines that are due at each visit by implementing client reminder and recall systems might decrease missed opportunities for simultaneous administration of childhood vaccines.

Conflict of interest statement: No conflicts of interest.

\section{References}

[1] National Vaccine Advisory Committee. Standards for child and adolescent immunization practices. Pediatrics 2003;112(958):63.

[2] Centers for Diseases Control Prevention. Recommendations of the Advisory Committee on Immunization Practices (ACIP). MMWR 2011;60(January (RR02)):1-60. 
[3] King GE, Hadler SC. Simultaneous administration of childhood vaccines: an important public health policy that is safe and efficacious. Pediatr Infect Dis J 1994;13:394-407.

[4] US Department of Health and Human Services. Healthy people 2020 objectives, immunization and infectious diseases. http://www.healthypeople.gov/2020/ topics-objectives/topic/immunization-and-infectious-diseases/objectives.

[5] Centers for Diseases Control Prevention. Immunization strategies for healthcare practices and providers. Epidemiology and prevention of vaccinepreventable diseases. The pink book: course textbook. 13th ed; 2015.

[6] Paul A, Offit PA, Quarles J, Gerber MA, Hackett CJ, Marcuse EK, et al. Addressing parents' concerns: do multiple vaccines overwhelm or weaken the infant's immune system? Pediatrics 2002;109(January (1)).

[7] Dietz VJ, Stevenson J, Zell ER, Cochi S, Hadler S, Eddins D. Potential impact on vaccination coverage levels by administering vaccines simultaneously and reducing dropout rates. Arch Pediatr Adolesc Med 1994;148:943-94.

[8] Centers for Disease Control Prevention. Early childhood vaccination in two rural counties: Nebraska, 1991-1992. MMWR 1992;41:688-91.

[9] Cutts FT, Zell ER, Mason D, Bernier R, Dini E, Orenstein WA. Monitoring progress towards US preschool immunization goal. JAMA 1992;267:1952-5.

[10] Luman ET, Chu SY. When and why children fall behind with vaccinations: missed visits and missed opportunities at milestone ages. Am J Prev Med 2009;36:105-11.

[11] National Immunization Survey (NIS) - Children (19-35 months) U.S. Vaccination Coverage Reported via NIS. Centers for Disease Control and Prevention. http://www.cdc.gov/vaccines/imz-managers/coverage/nis/child/index.html.

[12] Smith PJ, Hoaglin DC, Battaglia MP, Khare M, Barker LE. Statistical methodology of the National Immunization Survey, 1994-2002. Vital Health Stat 2005;2:138.

[13] Centers for Disease Control Prevention. National and state vaccination coverage among children aged 19-35 months - United States, 2010. Morb Mortal Wkly Rep 2011;60(34):1157-63.
[14] Centers for Disease Control Prevention. National, state, and local area vaccination coverage among children aged 19-35 months - United States, 2011. Morb Mortal Wkly Rep 2012;61:689-96.

[15] Centers for Disease Control Prevention. National, state, and local area vaccination coverage among children aged 19-35 months - United States, 2012. Morb Mortal Wkly Rep 2013;62(36):733-40.

[16] Elam-Evans LD, Yankey D, Singleton JA, Kolasa M. National, state, and loca area vaccination coverage among children aged 19-35 months - United States, 2013. Morb Mortal Wkly Rep 2014;63(34):741-8

[17] Recommended immunization schedules for persons aged 0 through 18 years-United States; 2015. http://www.cdc.gov/vaccines/schedules/ downloads/child/0-18yrs-pocket-pr.pdf.

[18] Smith PJ, Nuorti JP, Singleton JA, Zhao Z, Wolter KM. Effect of vaccine shortages on timeliness of pneumococcal conjugate vaccination: results from the 2001-2005 National Immunization Survey. Pediatrics 2007:120(November (5)):e1165-73.

[19] Research Triangle Institute. SUDAAN language manual, release 11.0. Research Triangle Park, NC: Research Triangle Institute; 2012.

[20] Wallacea AS, Mantelb C, Mayersb G, Mansoorc O, Gindlera JS, Hyde TB. Experiences with provider and parental attitudes and practices regarding the administration of multiple injections during infant vaccination visits: lessons for vaccine introduction. Vaccine 2014;32:5301-10.

[21] Blumberg SJ, Luke JV. Reevaluating the need for concern regarding noncoverage bias in landline surveys. Am J Public Health 2009;99:1806-10.

[22] Molinari NM, Wolter K, Skalland B, Montgomery R, Smith PJ, Khare M, et al. Quantifying bias in a health survey: modeling total survey error in the national immunization survey. Stat Med 2011;30(5):505-14.

[23] The Guide to Community Preventive Services. Increasing appropriate vaccination: client reminder and recall systems. http://www.thecommunityguide.org/ vaccines/clientreminder.html. 